\title{
CONSELHO DE SAÚDE: UMA REFLEXÃO SOBRE OS PROCESSOS DE PARTICIPAÇÃO DOS CONSELHEIROS
}

\author{
Liane Colliselli* \\ Kenya Schmidt Reibnitz** \\ Maria Elisabeth Kleba*** \\ Dunia Comerlatto*****
}

\begin{abstract}
Resumo
Este estudo tem como objetivo identificar os motivos que levam os conselheiros a se inserir, continuar e/ ou desligar-se do conselho municipal de saúde. Está sustentado teoricamente no conceito de participação de Bordenave e Demo. A metodologia utilizada baseia-se na abordagem qualitativa do tipo estudo de caso instrumental. Para a coleta de dados, utilizou-se análise documental, entrevistas individuais e observação. Os resultados apontam que os motivos referidos para iniciar, permanecer e se desligar incluem: convite ou indicação; o gostar e conceder oportunidade a outras pessoas. A participação, para além da presença física, demanda inúmeros recursos, como: conhecimento, tempo, acesso e compreensão das informações, articulação, comprometimento, descentralização do poder, entre outros. Neste sentido, a participação nos conselhos é um processo em construção que deve ser fortalecido para efetivar o exercício do controle social na área da saúde, conforme tem sido preconizado pela legislação brasileira.
\end{abstract}

Palavras-chave: Conselho de Saúde. Participação Comunitária. Gestão Participativa.

\footnotetext{
* Enfermeira, Mestre em Enfermagem. Docente do Curso de Enfermagem da Universidade Federal Fronteira Sul UFFS e integrante do Grupo de Pesquisa em Políticas Públicas e Participação Social da Universidade Comunitária da Região de Chapecó - Unochapecó. E-mail: liacol@unochapeco.edu.br

** Enfermeira. Doutora em Enfermagem. Docente do Programa de Pós-graduação em Enfermagem e do Departamento de Enfermagem/UFSC.E-mail: kenya@ccs.ufsc.br

**** Enfermeira. Doutora em Filosofia. Docente da Área de Ciências da Saúde e dos Mestrados em Políticas Sociais e Dinâmicas Regionais e em Ciências da Saúde; Coordenadora do Grupo de Pesquisa em Políticas Públicas e Participação Social da Universidade Comunitária da Região de Chapecó. E-mail: 1kleba@unochapeco.edu.br ***** Assistente Social. Doutora em Serviço Social. Docente da Área de Ciências Humanas e Jurídicas e do Mestrado em Políticas Sociais e Dinâmicas Regionais, integrante do Grupo de Pesquisa Políticas Públicas e Participação Social, da Universidade Comunitária da Região de Chapecó - Unochapecó. E-mail: dunia@unochapeco.edu.br.
} 


\section{Introdução}

A participação da sociedade na gestão das políticas de saúde no Brasil tem sido tema de discussão em todos os níveis de governo. Ela está garantida na Constituição Brasileira, nas Leis 8.800/90 e 8.142/90, na Resolução 333/03 e nos documentos que norteiam as diferentes políticas do Ministério da Saúde. Os preceitos legais da participação social nos Conselhos e Conferências estão garantidos, porém, muito ainda se questiona como de fato essa participação é colocada em prática: o que se entende por participação; como e quanto se participa. Participar vai além de estar presente, é fazer parte, garantir esta parte, envolvendo-se enquanto protagonista nas decisões da política pública na saúde. Para Bordenave (1994), a participação é uma vivência coletiva, não individual, na qual somente se aprende a participar, participando. Segundo Demo (1999), a participação é influenciada pela cultura, podendo ativar as potencialidades de uma comunidade e a sua capacidade de interagir com as circunstâncias externas. Segundo Carvalho (2007, p. 45), a participação deve ocorrer "pela ação, a proposição e o controle". A ação compreende o ato, o fazer, realizar, primando sempre à qualidade, a melhor maneira possível. A proposição requer apresentação de ideias, formulação de estratégias e deliberação. $\mathrm{O}$ controle, por sua vez, requer o acompanhamento, a fiscalização das ações planejadas e executadas, no caso do Conselho de Saúde, inclusive sobre a questão econômica e financeira. Participação no Conselho, na visão do autor, "é engajamento através da ação, é o desafio da proposição e o controle dos fatos e feitos”.

Para Kleba (2005), a participação cidadã requer o sentimento de pertencimento, o desejo de contribuir de forma responsável para o processo de desenvolvimento político e social. A democratização da gestão requer uma participação cidadã, onde as pessoas se envolvem e se comprometem nas discussões fundamentais para suas vidas.

Segundo o cadastro do Conselho Nacional de Saúde, realizado em 2005, o número de Conselhos municipais de saúde no Brasil era de 5.091, representando 91,07\% dos municípios brasileiros. Esses dados representam um número significativo. No entanto, o Conselho Nacional de Saúde reconhece que ainda existem muitos desafios para os gestores e conselheiros de saúde concretizar os pressupostos da gestão participativa (Brasil, 2002a), entre estes o exercício da representação que requer dos atores 
envolvidos habilidades de diálogo, com vistas a incluir interesses coletivos na agenda política.

Conforme dados disponíveis no site do Conselho Nacional de Saúde, no Sistema de Acompanhamento dos Conselhos de Saúde - SIACS - em fase de preenchimento a partir de junho de 2012, o número de Conselhos municipais de saúde no Brasil é de 5596, destes 3.552 encontram-se com o cadastro atualizado, representando 63,47\% dos municípios brasileiros. 1.158 (21\%) solicitaram acesso para recadastramento e 886 (15,8\%) não solicitaram acesso.

Esses dados são relevantes na medida em que demostram a transparência da organização dos conselhos de saúde. Ao analisar os dados identifica-se que ainda existem muitos desafios para os gestores e conselheiros de saúde na perspectiva de constituir os conselhos conforme as normas legais relacionadas ao Sistema Único de Saúde. Entre eles: o respeito à paridade (50\% usuários, $25 \%$ profissionais e $25 \%$ prestadores de serviços), a qual não é respeitada em 41\% dos conselhos (CNS, 2013).

Conforme a Resolução 333/03, os segmentos que compõem os conselhos de saúde são escolhidos para representar a sociedade como um todo. Os conselheiros devem ser indicados pelos respectivos segmentos, representando entidades da sociedade, de acordo com a sua organização ou de seus fóruns próprios e independentes.

Gerschman (2004, p. 1676) constatou que a escolha dos representantes no segmento dos usuários "é realizada, em geral, por meio de indicações ou eleições em assembleias gerais, nas sedes das Associações de Moradores e entidades religiosas e comunitárias". Numa frequência menor, 17\% dos representantes são escolhidos nas conferências municipais de saúde e $5 \%$ pelas diretorias das entidades à qual estão vinculadas. Já nos outros segmentos, as formas utilizadas para eleger os representantes têm pouca visibilidade. Para Kleba (2005, p. 273), embora a indicação dos representantes advenha das entidades e instituições que representam, "o gestor municipal tem influenciado na escolha das organizações que têm cadeira no Conselho, seja na definição destas, na Lei que estabelece sua criação, seja no convite a pessoas de sua confiança”. Relata que nos municípios contemplados em seu estudo raramente eram realizadas reuniões ou assembleias objetivando escolher os representantes ou debater sobre suas responsabilidades e competências, o que certamente determina a 
pouca articulação entre os representantes e a base representada. Presoto e Westphal (2005) identificaram que a maioria dos conselheiros ingressou a partir da indicação dos dirigentes de suas entidades de classe, desconsiderando a necessidade de envolver nesta escolha os demais membros de sua entidade ou ainda o interesse pessoal em participar. Este dado, na compreensão das autoras, remete ao risco de manipulação por parte do governo municipal quando, na indicação de representantes, aspira negociações políticas. Os processos de escolhas dos representantes são mecanismos importantes para oportunizar o acesso democrático da população às instâncias de decisão e de poder, devendo os conselheiros ser indicados pelas entidades ou movimentos a que pertencem, mediante discussão ampliada entre os pares (BRASIL, 2002b).

No intuito de desvelar avanços e desafios no exercício do controle social na gestão da política de saúde, o presente estudo tem seu foco na compreensão de conselheiros sobre seu processo de participação, buscando identificar os motivos que os levam a se inserir, continuar e/ou romper sua participação no Conselho de Saúde de Chapecó, SC.

\section{Metodologia}

O estudo contempla um objetivo especifico da dissertação de mestrado denominada "A compreensão dos conselheiros municipais de saúde sobre a participação social e seus processos”, defendida no ano de 2009 na Universidade Federal de Santa Catarina.

Trata-se de um estudo de caso instrumental com abordagem qualitativa. Para a coleta de dados, utilizou-se: análise documental, entrevista individual e observação. Teve como lócus o Conselho Municipal de Saúde de Chapecó, e como participantes, conselheiros titulares ativos dos três segmentos: prestadores de serviços de saúde (governamental e não governamental); profissionais de saúde e usuários do sistema que exerceram a representação pelo período de um ano ou mais, no período entre maio 2000 a 2009. O conselho municipal de saúde de Chapecó é composto por 28 conselheiros titulares e o mesmo número de suplentes em cada período de gestão.

Neste estudo, conselheiros titulares ativos são aqueles que apresentaram inserções de falas nas reuniões, causando movimento 
de debate e interação entre os diversos atores, resultando em proposições, discussão, acompanhamento, deliberações e fiscalização de políticas públicas na área da saúde. A análise documental inicial e as entrevistas individuais foram realizadas durante o ano de 2008 e a observação em 2009. Os dados obtidos na análise documental foram utilizados para definir a escolha dos participantes. Iniciouse com a obtenção de cópias das atas do Conselho Municipal de Saúde de Chapecó, referente ao período de maio de 2000 a abril de 2009, totalizando 120 atas. Para incluir os conselheiros na condição de ativos, buscou-se inicialmente o tempo de participação no conselho, o número de gestões e a representação, por meio da nomeação oficial dos conselheiros. As inserções das falas foram quantificadas e qualificadas, através da identificação registrada em ata, de forma que contemplassem categorias como proposição, discussão, acompanhamento, deliberação, avaliação e a fiscalização da Política de Saúde. Esse conjunto de características delineou a escolha dos 12 conselheiros entrevistados.

As entrevistas individuais seguiram um roteiro guia, sendo abordadas a compreensão e as vivências individuais relacionadas à participação. A observação não participante complementou a análise documental e as entrevistas individuais. Foram observadas duas reuniões do CMS realizadas em 2009, tendo como foco a participação dos conselheiros sujeitos da pesquisa participantes da atual gestão; a forma de registro foi o diário de campo.

Para a análise dos dados utilizou-se a análise temática proposta por Minayo (2008), buscando os núcleos de sentido que compõem a comunicação, cuja presença ou frequência foi significativa para o objetivo proposto. Os aspectos éticos estiveram presentes durante todo o período de execução seguindo os trâmites recomendados pela Resolução 196/96 do CNS.

$\mathrm{Na}$ apresentação dos resultados utilizaram-se nomes fictícios para os conselheiros, seguidos pelo segmento que representam, o número de gestões que permaneceram como conselheiros (as) e se no período em que foi realizada a pesquisa se encontravam na condição de conselheiros (as) em exercício ou ex-conselheiros (as).

\section{Resultados e discussão}

Nos resultados serão apresentadas e discutidas inicialmente questões relacionadas ao período de representação no Conselho, na sequência o perfil dos conselheiros entrevistados e, após, os 
motivos que os levaram a inserção, continuação e desligamento do processo participativo.

Quanto ao período de representação dos conselheiros estudados, $16,7 \%$ (dois) exerceram a representação durante uma gestão; $58,3 \%$ (sete) por um período de duas gestões consecutivas e $25 \%$ (três) pelo período de três gestões consecutivas. Entre os conselheiros contemplados no estudo, $25 \%$ permaneceram na representação pelo período superior ao estabelecido pela legislação. Observa-se que um conselheiro migrou do segmento profissional para o segmento governamental, e outro migrou do segmento prestador para usuário, mantendo seu vínculo no Conselho como representante, não apenas de outra entidade, mas de outro segmento.

$\mathrm{Na}$ Resolução 333/03, o item $\mathrm{V}$ da terceira diretriz que trata da organização do Conselho estabelece que o "mandato dos conselheiros será definido no Regimento Interno do Conselho, [...] sugerindo-se a duração de dois anos, podendo o conselheiro ser reconduzido, a critério das respectivas representações.” Em nível local, o Art. 6º Lei municipal № 5.511 (Chapecó 2009), dispõe que o "mandato dos membros do Conselho Municipal de Saúde será de dois anos, podendo o membro indicado pela entidade permanecer no máximo por dois mandatos consecutivos”. Esse período também estava determinado nas leis que antecederam a legislação atual e no regimento interno.

\section{O perfil dos Conselheiros}

Em relação ao perfil dos 12 conselheiros entrevistados, seis são do sexo masculino e seis feminino. A faixa etária varia entre 34 a 66 anos. Wendhausen (2002, p. 212) encontrou resultados semelhantes em seu estudo, compreendendo que "os conselheiros encontram-se numa faixa etária considerada de maturidade (entre 30 a 50 anos), e isto é coerente com a sua participação em uma instância onde é necessário ponderar determinados fatores para que se tomem decisões”. Não que isso seja garantia que as decisões sejam as melhores, mas poderia influenciar qualitativamente as deliberações. Por outro lado, Wendhausen e Rodrigues (2006) consideram a diferença de idade entre os participantes como um dado positivo para o funcionamento democrático deste fórum, pois as diferentes experiências que permeiam várias gerações 
podem evidenciar uma variedade de posições frente aos temas discutidos.

Em relação à escolaridade, $75 \%$ possuem curso superior, $17 \%$ ensino médio e $8 \%$ ensino fundamental. Entende-se que o perfil dos conselheiros pesquisados indica um elevado grau de formação, considerando que $75 \%$ têm nível superior, contemplado nos três segmentos representados. Apesar disso, Wendhausen e Rodrigues (2006, p. 7) enfatizam a importância da escolaridade em relação à participação, pois acreditam

[...] que a educação como formação à cidadania é um desses canais, à medida que a escolaridade possibilita o envolvimento potencial e criativo das pessoas com as coisas de seu mundo, alicerçada em componentes formativos, de empoderamento ('autopromoção'), de direitos e deveres dos atores sociais, de acesso à informação e ao saber, de habilidades, valores e liberdade de escolhas responsáveis.

Segundo o censo do IBGE realizado no ano de 2000, no município de Chapecó, apenas 7,08\% da população que corresponde à faixa etária dos representantes da sociedade no Conselho concluíram o curso superior (IBGE, 2000). Este dado conduz à seguinte reflexão, se por um lado o elevado grau de escolaridade dos representantes pode ser avaliado positivamente, por outro, em que medida os grupos menos favorecidos, com maior risco de vulnerabilidade (população indígena, cooperativas de reciclagem, entre outras) são representados e envolvidos nas decisões sobre as políticas na área da saúde.

As áreas de formação dos conselheiros compreendem: saúde, pedagogia, biologia, direito, filosofia e serviço social. A presença dos conselheiros das diferentes áreas enriquece o colegiado, diversificando os olhares e as opiniões, viabilizando a ampliação do debate.

Em relação à ocupação, 80,5\% dos que representam os profissionais atuam na área da saúde, enquanto os demais atuam em outras áreas, como do lar, voluntária, diretor executivo, avicultor e representante de associação.

Quanto à religião, evidencia-se que: $58,3 \%$ são católicos; $8,3 \%$ cristãos ortodoxos; $8,3 \%$ espíritas; $8,3 \%$ Testemunha de Jeová; 8,3\% referem não ter religião, e 8,3\% não responderam. Segundo Gerschman (apud WENDHAUSEN E RODRIGUES, 2006), a "Igreja Católica, com suas experiências de organização popular através das comunidades eclesiais de base, marca um 
período de transição à democracia e oposição ao regime militar, que colabora com o fortalecimento do Movimento da Reforma Sanitária”.

Para Kleba (2005), a Igreja Católica na região Oeste Catarinense, desempenhou um papel significativo na construção do Sistema Único de Saúde, através da organização da Pastoral da Saúde, desenvolvendo ações que contemplavam a promoção dos direitos humanos e estimulavam discussões sobre as políticas de saúde. Nesse sentido, Wendhausen e Rodrigues (2006, p. 9) consideram que os movimentos desencadeados pela Igreja Católica, ou de "outros movimentos de organização da sociedade civil, podem se tornar instrumentos de politização que tendem a construir políticas de saúde baseadas na experiência concreta de participação, empoderamento, democracia e cidadania”.

Ainda para Demo (1999), organizações como a Igreja podem se constituir em outro 'canal de participação' que não seja o de assentimento ao poder, desde que assuma formas conscientes e políticas de organização, ou seja, que tenha conhecimento de seus interesses inseridos em determinados contextos organizativos.

No que concerne à qualificação dos conselheiros para exercer a representação de forma participativa, considera-se de extrema relevância processos formativos que educam para a ação, para a proposição e para o controle das políticas na área da saúde.

Segundo Carvalho (2007), a oferta de atividades educativas deve ser ampliada e conduzida metodologicamente na perspectiva de formar conselheiros que atuem nas suas bases, como multiplicadores do saber relativo ao exercício do controle social. Entre os conteúdos essenciais para a capacitação, considerase de fundamental importância o conhecimento da realidade, tendo como base a legislação. Nesse sentido, Gohn (2004, p. 28) considera que os conselheiros devem,

[...] ter formação e consciência crítica, para terem como meta o entendimento do processo onde se inserem; entenderem, por exemplo, a questão dos fundos financeiros públicos e os critérios que deveriam pautar seu uso para a eliminação da pobreza e das desigualdades sociais, para o atendimento das necessidades da população, segundo escalas de urgências e emergências.

No presente estudo, os dados demonstram que 83,3\% dos conselheiros participaram de capacitações relacionadas ao exercício do controle social. 
Eu participei, [...] de vários [cursos], tanto aqui [...] quanto a nível

estadual (Benjamin, Prestador, 02 Gestões, Ex Conselheiro).

Sim, aqui no SESC, fazem uns 5 ou 6 anos [...] (Atália, Usuária, 03 Gestões, Conselheira em exercício).

Sim, várias vezes, eu fui conselheiro municipal de saúde desde 1989 em Curitiba, eu participei da Conferência Nacional de Saúde que criou o SUS em 1988, a 10ª Conferência, então eu lido com isso há muito tempo, fui eu que no Estado do Paraná o primeiro a dar cursos de capacitação para conselheiros nas comunidades do interior, então eu tive essa formação em Brasília, e depois estendi, trabalhei muito anos no Paraná com isso (Emanuel, Profissional, 01 Gestão, Ex Conselheiro)

Avalia-se de forma positiva o elevado percentual de conselheiros que realizaram capacitações. Entende-se que este fato qualifica o debate no Conselho e contribui no aprendizado individual dos conselheiros. Em relação ao local onde foram realizadas as capacitações, foram mencionados os três níveis, porém, predominou o nível local, onde o grupo de pesquisa de Políticas Públicas e Participação Social - GPPPS da Unochapecó se inclui entre as entidades que promoveram as capacitações.

As capacitações realizadas pelos integrantes do grupo de pesquisa, conforme Kleba e colaboradores (2007), foram uma iniciativa da parceria entre a Unochapecó e o Pólo de Educação Permanente em Saúde no Oeste de Santa Catarina, que além de instrumentalizar os conselheiros para uma intervenção crítica propositiva, visavam promover a troca de experiências e a articulação entre diferentes atores engajados na construção das políticas públicas da região.

\section{Os motivos da participação no Conselho}

\section{A inserção no Conselho Municipal de Saúde}

Participar em algum espaço vem ao encontro de um objetivo pessoal ou de algum interesse coletivo. No caso dos conselhos gestores, a participação é fruto de uma conquista historicamente construída pelos movimentos sociais e outros segmentos sociais, legalmente instituída a partir da Lei № 8.142/90 e normatizada pela Resolução CNS/333/03. Esta prevê a participação paritária do segmento dos usuários em relação aos profissionais de saúde 
e aos prestadores de serviços de saúde, através de entidades ou instituições formalmente constituídas. Ou seja, o conselheiro representa uma organização formalmente instituída, parte de um segmento social. Esta forma de conduzir a participação requer das entidades ou instituições critérios para eleger os seus representantes. Entre os critérios utilizados podem ser citadas a eleição do representante pelos membros da organização, geralmente realizada por meio de assembleia geral, ou sua indicação pela direção da entidade. $\mathrm{O}$ estudo viabilizou identificar duas formas de iniciar a participação no Conselho: a indicação (oito) e o convite (quatro).

A indicação: Entre os entrevistados no presente estudo, o início da participação se deu, na maioria, por meio da indicação pelo presidente da entidade ou pelo gestor das instituições, conforme representado nas seguintes falas.

[...] foi bem lá no início do SUS, [...] Iniciei porque eu já trabalhava na secretaria de saúde, daí a própria entidade me pediu para ser representante. (Madalena,Profissional/Governo, 02 Gestões, Conselheira em exercício)

$[\ldots]$ o governo $[\ldots]$ tinha cadeira cativa no Conselho [...] e dessa forma eu fui incorporado como Conselheiro. (Tiago, Governo, 02 Gestões, Conselheiro em exercício)

[...] indicada pelo presidente da [...]. Não, por eleição não! [...] Como eu tenho mais tempo que eles, então eu fiquei direto, até agora, enquanto eu não enjoar. (Atália, Usuária, 03 Gestões, Conselheira em exercício)

Estes dados evidenciam que a indicação seguiu distintas conduções. O Tiago se diz incorporado pelo fato da instituição à qual ele está vinculado ter direito a ocupar uma vaga. Nesta inserção, evidencia-se o compromisso; não está explícito o desejo, a vontade de assumir a representação, relevantes para o planejamento de políticas públicas visando o coletivo. Nesta mesma lógica, considera-se a inserção da Madalena. No entanto, ao levar em consideração o perfil desses conselheiros, a escolha talvez pudesse ser justificada a partir do nível de conhecimentos na área da saúde que na representação é um recurso extremamente significativo. Na fala da Atália, a indicação apresenta uma relação direta com a disponibilidade do tempo, imprescindível para o exercício da representação, mais ainda quando este representa a 
sociedade civil organizada, mas que não pode ser o único critério para compor o colegiado.

No estudo observou-se ainda, que a indicação ocorreu igualmente no segmento dos prestadores, (governamental (dois) e não governamental (dois)), dos profissionais de saúde (dois) e dos usuários (dois). Considera-se que no segmento dos usuários as escolhas das representações deveriam seguir critérios mais democráticos e transparentes, como a eleição.

O Convite: No que concerne ao convite, também se evidencia distintos encaminhamentos. $\mathrm{O}$ convite é direcionado às pessoas, conforme depoimento a seguir: "[...] fui convidado [...] tinha feito um curso de especialização em saúde pública, tinha contato maior com as pessoas. [...]" (Davi, Profissional, 01 Gestão, Ex Conselheiro)

Evidencia-se, no transcorrer deste estudo, que o representante que assume a participação com o objetivo de garantir o bem coletivo do planejamento e a consolidação das políticas públicas, incorpora a participação como um compromisso cidadão, visando, conforme Bordenave (1994), à intervenção nos processos dinâmicos que constituem e modificam a sociedade.

O convite oriundo do Conselho é direcionado para a entidade, e, muitas vezes, quem assume a representação é a pessoa que exerce cargo de chefia nessa ocasião.

Eu não me lembro se fui convidada, eu acho que não. [...] A gente entrou em contato com o Conselho para que a nossa associação fosse representada. Aí, como eu era a presidente na época, [...] participamos do processo eleitoral [concorrendo com outras entidades por uma vaga no Conselho]. (Anícia, Profissional, 03 Gestões, Conselheira em exercício)

Nessa forma de inserção percebe-se a ausência de envolvimento da base, dos segmentos representados, uma vez que o representante utilizou-se do cargo que exercia para assumir a representação. Este modo de inserção pode ser compreendido de diferentes maneiras: por um lado, podemos atribuí-la à falta de envolvimento, de participação da base, por outro, a confiança à pessoa que está na condução da entidade, possivelmente considerada como a pessoa mais qualificada, com maior domínio do conhecimento, ou ainda, como exercício centralizado do poder, não possibilitando o envolvimento de outras pessoas do 
mesmo segmento. Esta última, sem dúvida, representa a posse, a apropriação, prevalecendo o interesse individual sobre o coletivo.

\section{A permanência no Conselho Municipal de Saúde}

Permanecer como representante de uma entidade e/ ou segmento no Conselho Municipal de Saúde compreende distintas justificativas. Algumas avaliadas positivamente, e outras, demonstrando os limites com que a participação social ainda convive.

O compromisso: Inicia-se refletindo sobre as razões que se compreendem positivas, uma vez que vêm ao encontro da consolidação do Sistema Único de Saúde, percebendo e assumindo esta representação como um compromisso não só profissional, mas, acima de tudo, cidadão, capaz de influenciar nos processos dinâmicos da sociedade, apresentado nas falas que seguem.

Eu atuo na saúde pública há 30 anos. Acompanhei todo o processo

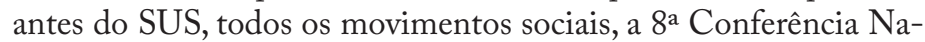
cional de Saúde, a Constituinte, depois a Constituição Federal, a LeiOrgânica 8.142 [...]. O desejo de fortalecer o SUS, [...] fazer com que [...] a política de estado se efetive e faça com que menos pessoas morram, que as pessoas vivam mais felizes com mais saúde, é o que me faz persistir a continuar até o último dia de trabalho na vida ativa. (Tiago,Governo, 02 Gestões, Conselheiro em exercício)

[...] para contribuir na área da saúde. [...] Eu trabalho na área da saúde; [...] a gente pode contribuir. (Pedro, Prestador, 02 Gestões, Ex Conselheiro)

“... a preocupação com a direção da política de saúde. (Antônia, Governo, 02 Gestões, Ex Conselheira)

[...] é o grande problema que tem na rede pública de saúde e um dos pontos que eu sempre pensei era defender que as verbas públicas sejam gastas dentro da saúde pública de Chapecó, sejam bem aplicadas, [...], ajudando a resolver alguns dos problemas e pesquisando. (Elias, Usuário, 03 Gestões, Conselheiro em exercício)

Ao refletir sobre os motivos mencionados acima, constata-se que nos três segmentos existe uma inquietação frente à condução do Sistema de Saúde. Na fala do Tiago, confirma-se uma trajetória pessoal de acompanhamento do processo de construção do SUS. 
Manifesta que seu objetivo é melhorar a qualidade de vida das pessoas. Na fala do Elias, também se evidencia a preocupação com o que é público, associada a um desejo dos representados, fato este que torna o representante mais legítimo, associado a um processo de escolha mais democrática, conforme cita, “... e se for eleito”. Neste sentido, Bordenave (1994) afirma que, apesar de a participação ser uma necessidade básica, o homem não nasce sabendo participar, mas que é uma habilidade que se constrói e se aperfeiçoa ao passar do tempo, sofrendo influência direta da cultura participativa da comunidade.

O gostar: Partindo do princípio de que a participação é própria da natureza social do homem, foi possível constatar que o "gostar de participar" é uma das razões pela qual os representantes permaneceram, o que fica explicitado nas falas a seguir.

(...) acreditar nas coisas. A partir do momento que você acredita no que está fazendo, você quer fazer isso [...]. A entidade voltou a me procurar. (Madalena, Profissional/Governamental, 02 Gestão, Conselheira em exercício)

Porque eu gosto, [...] porque o convite foi mantido após a eleição [...] e por que eu acho que eu tinha uma contribuição à dar. (Davi, Profissional, 01 Gestão, Ex-Conselheiro)

(...) eu gosto de participar [...], as pessoas me procuram [...] eu me sinto gratificado com isso, com vontade de seguir até que minha vida aguente, e se for eleito. (Elias, Usuário, 03 Gestões, Conselheiro em exercício)

Percebe-se que o "gostar" vem permeado de outros atributos, como o acreditar que sua contribuição é importante e capaz de intervir nos processos da sociedade. Compreende-se que o gostar de participar supramencionado reflete o sentimento de pertencimento, componente essencial para construir um projeto de vida e, por extensão, um projeto de sociedade. Este pertencer se reflete diante da solicitação dos representados para a continuidade na representação, tornando-a mais legítima, com maiores possibilidades de participar efetivamente na construção de políticas públicas na área da saúde.

O saber: Outro motivo pelo qual houve continuidade na participação contempla o saber, fruto das possibilidades advindas da participação em cursos de capacitação relacionados ao exercício do controle social, conjugado com a responsabilidade diante do 
coletivo, conforme fala a seguir: “... vai se capacitando, vai se apropriando, é importante a gente permanecer...” (Benjamin, Prestador, 02 Gestões, ex- conselheiro)

Esta continuidade reflete que a participação no Conselho é um processo, em que a qualificação obteve um peso relevante para prosseguir a representação. A permanência para além de um período de gestão oportuniza o apropriar-se, favorecendo uma maior compreensão sobre o funcionamento e a dinâmica do Conselho, conferindo maior domínio frente à tomada de posição.

Compreende-se que os motivos acima relatados favorecem muitas vezes a permanência dos representantes no conselho por um período superior ao definido no Regimento Interno, que prevê a representação pelo período de dois anos renovável pelo mesmo período. Por um lado, isso pode contribuir no exercício do controle social, uma vez que são motivados pelo compromisso, pela responsabilidade e pelo desejo de intervir nas políticas públicas na perspectiva de melhorar a qualidade de vida das pessoas. Por outro lado, essa prática pode limitar o compartilhamento do poder com outras pessoas de sua entidade ou segmento, o que, às vezes, se caracteriza como profissionalização da representação do controle social.

A falta de opção: No entanto, constata-se que nem sempre a representação é uma opção, um desejo, conforme segue.

Por que ninguém quer entrar no meu lugar. (Antônia, Governo, 02 Gestões, Ex Conselheira)

O presidente da [...] pediu para que eu ficasse porque ele falou que eu quebro um galho para eles, por causa da saúde. E daí, quando precisa levar alguma notícia para eles, [...] eu sou a ponte dos dois. (Atália, Usuária, 03 Gestões, Conselheira em exercício)

[...] no primeiro e segundo mandato eu era da associação [...], não tinha ninguém que tinha interesse, $[\ldots]$ então ficou sobrando. [...] Eu sempre gostei [...] de participar [...] dessa questão política de trabalhar em prol da comunidade. Você não está fazendo nada em relação a você. No inicio eu tinha uma visão muito de defesa da categoria, mas agora eu vejo que realmente a questão é defesa da saúde [...] para a comunidade; não só como município, como também algumas ações, em relação ao Brasil. (Anícia, Profissional, 03 Gestões, Conselheira em exercício) 
Constata-se na fala da Anícia que, inicialmente, assumiu a representação por falta de opção, mas que ao longo do processo desencadeou outro sentimento. $\mathrm{O}$ que vem ao encontro de Bordenave (1999), quando afirma que o homem não nasce sabendo participar, mas que ele vai construindo ao passar do tempo, na mesma perspectiva de Freire (1993), quando se refere ao homem como um ser de relações, no mundo e com o mundo, num constante processo de ação-reflexão-ação.

Ao refletir sobre os motivos considerados como limitantes da participação, compreende-se que os processos democráticos de participação ainda são muito frágeis, especialmente quando se considera as falas que têm origem no segmento dos usuários. Esta constatação reflete a necessidade de desenvolver ações na sociedade que ampliem os conhecimentos na perspectiva da construção da cidadania. Compreende-se que ações desta natureza devem ser contempladas nos Planos Políticos Pedagógicos dos cursos na área da saúde. Enfatiza-se aqui especialmente, o curso de Enfermagem, que contempla, nas Diretrizes Curriculares Nacionais, a inserção do profissional enfermeiro no planejamento das políticas públicas na área da saúde. Esta determinação encontra-se no Art. $3^{\circ}$ onde consta que o "Curso de Graduação em Enfermagem tem como perfil [...] do egresso [...] formar um profissional capacitado a atuar, com senso de responsabilidade social e compromisso com a cidadania, como promotor da saúde integral do ser humano". Ainda, no Art. $5^{\circ}$, relativo às competências e habilidades do profissional enfermeiro prevê, na competência XXX - "participar da composição das estruturas consultivas e deliberativas do sistema de saúde"; e na competência XXXIII - "reconhecer o papel social do enfermeiro para atuar em atividades de política e planejamento em saúde" (CONSELHO NACIONAL DE EDUCAÇÃO, 2001). Em relação ao enfermeiro que atua na atenção básica, cabe-lhe ainda, como integrante da equipe da Estratégia Saúde da Família, intervir diretamente na comunidade, fortalecendo a participação no controle social, no planejamento, na execução e na avaliação das ações em saúde (MINISTÉRIO DA SAÚDE, 2006).

Considera-se que é compromisso das instituições formadoras inserir os estudantes em cenários de estudo reais, dentre eles, as instâncias que pensam o coletivo, no caso, os Conselhos gestores de políticas públicas. Acredita-se que estas iniciativas 
poderão desencadear processos participativos na perspectiva do compromisso profissional e cidadão.

\section{O desligamento do Conselho Municipal de Saúde}

Conforme a legislação que prevê a participação no conselho de saúde, a representação é exercida por um período determinado. Dessa forma, em um dado momento ocorre à ruptura da representação exercida por uma pessoa, o Conselheiro.

Ao analisar as respostas dos entrevistados, constata-se entre os motivos que conduziram ao desligamento o de conceder a oportunidade a outras pessoas, conforme segue.

[...] eu estava cansada! Sabe essa coisa de ser sempre as mesmas pessoas? [...] Eu achava que estava na hora de outros assumirem. Eu retornei por que por que a entidade voltou a me procurar (Madalena, Profissional/Governamental, 02 Gestões Conselheira em exercício).

[...] é que participo de outros Conselhos, [...] é para dar oportunidade a outros a participar. (Davi, Profissional, 01 Gestão, Ex Conselheiro)

[...] é importante que outras pessoas participem dos Conselhos. (Bethânia, Usuária, 02 Gestões, Ex Conselheira)

Ao refletir sobre as falas da Bethânia e Davi, constatouse que entre os motivos que os levaram a romper a participação está o desejo de oportunizar o exercício da representação a outras pessoas. A fala de Davi evidencia que ele rompeu a representação legal nesse colegiado, mas envolveu-se em outros espaços que também requerem a participação da sociedade. Já na fala da Madalena, existe o desejo de oportunizar a participação a outros, em consequência de a representação estar centralizada na pessoa dela, refletindo pouco envolvimento do segmento que representa. Diante desta reflexão, considera-se que desligar-se em favor de oportunizar a participação a outras pessoas da sociedade vem ao encontro de possibilitar o exercício da cidadania.

Entre os outros motivos do desligamento, está presentes a mudança do gestor, a indicação de outro representante pelo presidente e a falta de tempo.

Mudança de governo. (Antônia, Governo, 02 Gestões, Ex Conselheira) 
[...] a troca de indicação, por decisão da associação, da presidência. (Pedro, Prestador, 02 Gestões, Ex Conselheiro)

Falta de tempo. (Emanuel, Profissional, 01 Gestão, Desligou-se)

Considerando que os representantes governamentais são trocados ao término do mandato, a justificativa da Antônia está coerente com a dinâmica de funcionamento do Conselho, estabelecida na legislação. A fala do Pedro é enfática: o presidente decidiu, logo, o representante acatou a decisão. Esta condução evidencia uma centralidade na decisão, exercida pelo presidente. A falta de tempo também foi considerada como um motivo. Considera-se que o tempo é um recurso imprescindível na participação, uma vez que requer do representante a presença física durante as reuniões do Conselho.

Dessa forma, constata-se que os motivos que conduziram ao desligamento da representação no Conselho de Saúde foram diversificados, alguns partindo de iniciativas individuais, outros devido a condições pré-determinadas pelos segmentos representados. Não aparecem nos relatos, no entanto, sentimentos negativos relacionados à vivência no Conselho que tivessem determinado a ruptura dos representantes com este fórum deliberativo.

O processo de ruptura, assim como de inserção no Conselho, pode provocar situações de conflito entre interesses pessoais e coletivos. Na medida em que a vivência experienciada promove o sentimento de pertencimento ao grupo, com o qual o representante constrói e compartilha saberes e práticas, este pode enfrentar dificuldades no momento de concluir seu mandato. No entanto, o processo de ruptura não se dá apenas com os conselheiros, reflete-se como descontinuidade na condução do próprio Conselho, uma vez que faltam mecanismos de comunicação mais efetivos tanto neste fórum, quanto nas organizações representadas, que possam garantir uma participação mais efetiva das bases representadas.

Desligar-se como representante de um conselho, não implica romper em definitivo sua ligação; qualquer e todo cidadão pode contribuir com os debates e influenciar nas decisões políticas, participando de comissões e das plenárias do conselho, das conferencias de saúde, mas também promovendo relações dialógicas nos espaços das organizações representadas, 
qualificando a participação de seus representantes no Conselho. A democratização da gestão publica requer, neste sentido, maior investimento em práticas participativas e democráticas no interior das organizações e da própria sociedade como um todo.

\section{Considerações finais}

O estudo realizado no município de Chapecó aponta que os conselheiros encontram-se numa faixa etária considerada de maturidade, com elevado nível de escolaridade, com formação e atuação em áreas diversificadas. Considera-se como potencialidade no Conselho o elevado número de conselheiros que participaram de eventos de capacitação afins a esta área de atuação, fator este que contribui na qualidade da participação neste fórum. Entende-se que a possibilidade do acesso às capacitações se justifica, primeiro, pela oferta de cursos no período em estudo e, segundo, ao tempo de permanência dos conselheiros na representação.

Os motivos que conduziram ao exercício da participação no Conselho foram na maioria pela indicação do gestor ou do presidente da Instituição/Entidade, e em menor proporção através do convite pessoal à Organização. Frequentemente, quem assume a representação é o próprio dirigente da entidade. Compreende-se que as formas de inserção no Conselho ainda estão centralizadas, e necessitam avançar na perspectiva de envolver a base, utilizando meios considerados mais democráticos, como a eleição, para a escolha dos representantes.

Partindo da análise documental, identificou-se que 25\% dos entrevistados, envolvendo o segmento dos usuários e dos profissionais, permaneceram por um período superior ao previsto na legislação. Esta evidência é relevante, uma vez que limita o envolvimento de outras pessoas em espaços próprios da participação social. Neste mesmo sentido, também ocorreu a migração de representantes entre os segmentos. Condição essa que pode ser utilizada para ampliar o período de representação no Conselho, limitando a inserção de novos atores neste cenário.

Os dados revelam, ainda, que um percentual significativo de conselheiros em exercício como representante pelo período de duas gestões, considerado legal, conforme legislação vigente. Diante desta constatação, identificou-se: o compromisso, o gostar, o saber, mas também a falta de opção, entre os motivos que 
justificam a permanência no Conselho. Avalia-se como fatores positivos o compromisso, o gostar e o saber, porque refletem o caminho que conduz a consolidação do Sistema Único de Saúde e o exercício da participação cidadã. Preocupa a permanência no Conselho, justificada como a falta de opção, especialmente porque a origem é do segmento dos usuários. Esse dado evidencia a necessidade de mobilizar a sociedade e viabilizar processos de educação permanente com vistas à participação e à construção da Cidadania.

Diante desta constatação, recomenda-se aos profissionais de saúde, reconhecer e assumir o seu papel social, desenvolvendo ações que venham ao encontro da qualificação da categoria e da sociedade na perspectiva da participação social.

Considerando que a participação no CMS é temporária, optou-se pela identificação dos motivos que justificam a ruptura da participação. Obteve-se, entre as respostas, a possibilidade de proporcionar a participação a outras pessoas, a mudança de governo e a falta de tempo. Entende-se que o fato de desligar-se, na perspectiva de possibilitar à participação ao maior número de pessoas, vem ao encontro da representação democrática, cidadã, permitindo que outras pessoas conheçam, aprendam e vivenciem o exercício do controle social.

Acredita-se que este estudo contribui na perspectiva de visualizar possibilidades que venham ao encontro do planejamento de ações que qualifiquem e fortaleçam a participação da sociedade no exercício do controle social e da cidadania. Nesta perspectiva, são reconhecidos como potencialidades os espaços de formação profissional, como as universidades e os cenários de prática, especialmente onde atuam os profissionais inseridos nas equipes da Estratégia Saúde da Família, a quem as políticas governamentais têm atribuído papel relevante como lideranças em seu envolvimento e comprometimento na construção de políticas públicas na área da saúde.

\section{Referências}

BORDENAVE, J. D. O que é participação. 8. Ed. São Paulo: Brasiliense, 1994. (Coleção Primeiros Passos 95).

BRASIL, Lei 8.142, 28 de dezembro de 1990. Dispõe sobre a participação da comunidade na gestão do SUS e sobre as transferências 
intergovernamentais de recursos financeiros na área de saúde e dá outras providências. Brasília, 1990. Disponível em: <http://www.conselho. saude.gov.br>. Acesso em: 15 ago. 2008.

BRASIL. Resolução CNE/CES n¹133 de 2001. Diretrizes Curriculares Nacionais do Curso de Graduação em Enfermagem. Disponível em: <http://portal.mec.gov.br/cne/arquivos/pdf/CES03.pdf>. Acesso em: 15 out. 2009.

BRASIL. Ministério da Saúde. Conselho Nacional de Saúde. A Prática do controle social: Conselhos de Saúde e financiamento do SUS / Ministério da Saúde, Conselho Nacional de Saúde. Reimpressão. Brasília: Ministério da Saúde, 2002a.

BRASIL. Guia do conselheiro: curso de capacitação de Conselheiros Estaduais e Municipais de Saúde. Brasília: Ministério da Saúde, 2002b.

BRASIL. Ministério da Saúde. Portaria No 648/GM de 28 de março de 2006. Aprova a Política Nacional de Atenção Básica, estabelecendo a revisão de diretrizes e normas para a organização da Atenção Básica para o Programa Saúde da Família (PSF) e o Programa Agentes Comunitários de Saúde (PACS). Disponível em: http://www.saude.sc.gov.br/ gestores/Pacto_de_Gestao/portarias/GM-648.html. Acesso em: 22 set. 2009

CARVALHO Gilson de Cássia Marques de. Participação da comunidade na saúde. Passo Fundo: IFIBE; CEAP, 2007.

CHAPECÓ LEI No 5.511 de 13 de março de 2009. Estabelece nova composição estrutura de Funcionamento do Conselho Municipal de Saúde e dá outras providências. Chapecó, 13 de março de 2009.

CONSELHO NACIONAL DE SAÚDE, Resolução n.333/2003, de 04 de novembro de 2003. Dispõe sobre o Conselho Nacional de Saúde. Disponível em: <http://conselho.saude.gov.br/>. Acesso em: 10 mai. 2008.

CONSELHO NACIONAL DE SAÚDE. Cadastro Nacional de Conselhos de Saúde, 2005. Disponível em: <http://conselho.saude.gov. br/web_cadastro/index.html>. Acesso em: 10 mai. 2008.

CONSELHO NACIONAL DE SAÚDE. Sistema de Acompanhamento dos Conselhos de Saúde, 2012. Disponível em: <http://conselho.saude.gov.br/web_siacs/index.html>. Acesso em: 19 nov. 2013 CONSELHO NACIONAL DE SAÚDE. Resolução no 196, de 10 de outubro de 1996, que aprova as Diretrizes e Normas Regulamentado- 
ras de Pesquisas Envolvendo Seres Humanos. Disponível em: <http:// www.conselho.saude.gov.br/resolucoes/reso_96.htm>. Acesso em: 20 nov. 2008.

DEMO Pedro. Participação é conquista. 3. Ed. São Paulo: Cortez, 1999.

FREIRE, Paulo. Educação e mudança. 19. ed. Rio de Janeiro: Paz e Terra, 1993.

FUNDAÇÃO INSTITUTO BRASILEIRO DE GEOGRAFIA E ESTATISTICA. Censo 2000. Disponível em: <http://www.censo2010. ibge.gov.br/dimensoes.php>. Acesso em: 23 out. 2009.

GERSCHMAN, Silvia. Conselhos municipais de saúde: atuação e representação das comunidades populares. Caderno de Saúde Pública, Rio de Janeiro, v.20, n.6, p. 1670-1681 nov./dez., 2004.

GOHN, Maria da Glória. Empoderamento e participação da comunidade em políticas sociais. Saúde e Sociedade, São Paulo, v.13, n2 p.2031, maio/ago, 2004.

KLEBA, Maria Elisabeth. Descentralização do sistema de saúde no Brasil: limites e possibilidades de uma estratégia para o empoderamento. Chapecó: Argos, 2005.

KLEBA, Maria Elisabeth; COMERLATTO, Dunia; COLLISELLI, Liane. Promoção do empoderamento com conselhos gestores de um pólo de educação permanente em saúde. Texto Contexto - Enfermagem, Florianópolis, v. 16, n. 2, p.335-342, 2007.

MINAYO, Maria Cecília de S. O desafio do conhecimento. Pesquisa qualitativa em saúde 11. Ed. São Paulo: Hucitec, 2008.

PRESOTO, Lucia Helena; WESTPHAL, Márcia Faria. A participação social na atuação dos conselhos municipais de Bertioga - SP. Saúde Sociedade, São Paulo, v. 14, n. 1, p.68-77, 2005.

WENDHAUSEN, Àgueda. O duplo sentido do controle social: (des) caminhos da participação em saúde. Itajaí: UNIVALI, 2002.

WENDHAUSEN, Águeda L. P.; BARBOSA, Tatiane Muniz.; BORBA, Maria Clara de. Empoderamento e recursos para a participação em conselhos gestores. Saúde Sociedade,[on line], vol.15, n.3, p.131-144. Dec. 2006. Disponível em: <http://www.scielo.br/scielo. 
php?pid=S0104-12902006000300011\&script=sci_arttext $>$. Acesso em: 20 jun. 2009.

WENDHAUSEN, Á. L. P.; RODRIGUES, Ivia. Concepções de saúde de conselheiros municipais de saúde da região da AMFRI/SC e a relação com a prática no Conselho. Ciência, Cuidado e Saúde, Brasil, v. 5, n.2, p. 166-174, mai./ago., 2006. Disponível em: <http://periodicos.uem.br/ojs/index.php/CiencCuidSaude/article/view/5072/3291>. Acesso em: 10 mar. 2009.

\title{
HEALTH COUNCIL: A REFLECTION ABOUT THE COUNCILORS' PROCESSES OF PARTICIPATION
}

\begin{abstract}
This study aims to identify the reasons that lead councilors to join the municipal Council of health, as well as to continue to participate and/or disconnect from his/her activities. It is theoretically based on Bordenave and Demo's participation concept. The methodology is based on the qualitative approach, being an instrumental case study. A documental analysis was prosecuted,and individual interviews and observation were carried out to collect the data. For data collection, document analysis, personal interviews and observation. The results indicate that the reasons given to start, stay and turns off include: invitation or indication; the like and grant opportunity to others. The participation, in addition to the physical presence, demand numerous features such as: knowledge, time, access to and understanding of information, coordination, commitment, decentralization of power, among others. Accordingly, the participation in the councils is a process under development which has to be strengthened to favor the exercise of social control in the health area, according to what has been stated in the Brazilian legislation.
\end{abstract}

Keywords: Consumer Participation. Health Councils. Participatory Management

REVISTA GRIFOS - N. 32/33 - 2012 